\title{
Bodil Helder 2011. Textual Analysis. An Approach to Analysing Professional Texts. Samfundslitteratur, 239 pages. ISBN 978-87-593-1568-2
}

\section{Introduction}

Textual Analysis. An Approach to Analysing Professional Texts is a book mainly intended for students in communication at university level. It proposes a comprehensive set of theoretical and practical elements which enable students to get the deepest insights into professional texts and to perform well-organized, multilayered textual analyses. This book is an application of the Gricean maxims for (a) it is 'as informative as' necessary for students in communication, for (b) all the theoretical issues are supported by adequate evidence and for (c) its author's relevance (or 'knowledge of the current topic', p. 119) is obvious throughout the book as well as (d) his way of styling the book into a concise and orderly expression, avoiding any obscurity or ambiguity.

\section{Summary of contents}

The volume consists of ten chapters: 1. The Framework; 2. Genre; 3. Communicative purpose; 4. Move structures; 5 . Text types - modes of writing; 6 . Rhetorical strategies I: topic; 7. Rhetorical strategies II: sender's attitude and sender/receiver relationship; 8. Rhetorical strategies III: textual aspects; 9. Rhetorical strategies IV: tropes and figures; 10. Summary-analysis sheet. They are followed by an Appendix which furthers on tropes and figures, by References and an Indeks of key terms. Each chapter shows a nearly similar format: theoretical contributions briefly revisited and resumed are supplemented with new concepts to provide readers with up-to-date analysis perspectives; these models are followed by relevant classifications, carefully selected examples of text (types) and their entailed commentaries. Then, a chapter summary synthesizes its main ideas. Nevertheless, the first and the final chapters are quite different from the traditional patterns. Thus, the first chapter focuses primarily on theoretical issues related to text-external features, such as social context, sender, receiver and medium which are not expanded in other chapters. Secondly, the chapter also discusses the text-internal features which are detailed in specifically designed chapters, such as genre, for one example only. The final chapter, in its list-like form, is both a general survey of the book and an inclusive list of questions addressing the key issues discussed under each chapter.

In the first chapter, the author reminds two rather similar models of communication, i.e. Laswell's (1948) and Jakobson's (1960) which he merges into his own simple and suggestive representation, the Analysis Model (fig. 1.2, p. 10). This model of the communication act specifically tailored consists for textual analyses consists of four equally important elements, social context, sender, receiver and genre/purpose/medium which are encapsulated into equal circles symmetrically distributed around a larger circle which backgrounds the notions of Text/code as they are the object of any textual analysis. Each element of the analysis model is given a more or less detailed description. It is only within the section preceding the summary which synthetically suggests the book structure devised in a cause-effect type of relationship. Therefore, to successfully perform a professional text analysis (whose basic instruments are enumerated in chapter 1), an analyst should identify the text genre and purpose (features which are accurately described in chapter 2) and determine the text communicative purpose (detailed in chapter 3) as well as the move structure (presented in chapter 4) which, in turn requires 'specific modes of writing' (developed in chapter 5). Since the text genre analysis relies considerably on language use and rhetorical strategies, this latter topic is displayed into the next four chapters, which approach topic-related rhetorical strategies (chapter 6), sender's attitude- and sender/receiver relationship-related rhetorical strategies (chapter 7), textual aspect-related rhetorical strategies (chapter 8), and trope- and figure-related rhetorical strategies (chapter 9).

Chapter 2 starts from the author's conviction that 'most people intuitively know how to classify a 
text in terms of genre' (p. 27). Nonetheless, the identification of a genre requires specific knowledge of text form, text function and of genre-influencing factors, such as 'discourse communities' - a notion associated with 'register' (p. 30). In addition, approaches to genre analysis have to consider assigning the text in question to a certain type of perspective which is determined by the text focus. Thus, (1) in linguistic perspectives, the emphasis lies on the lexical, morphological and syntactic levels, (2) in sociological perspectives, the focus is on the text-external and -internal features or on the way a genre addresses a (certain) professional group, and (3) in psychological approaches, the attention is centred on the way of thinking within a profession. This chapter also discusses the relationship between genre and persuasion, with the latter based on the three traditional appeal forms, i.e. logos (i.e. persuasion through reasoning), pathos (or persuasion through emotions) and ethos (that is, persuasion achieved through the text author's personality and character). Since logos creates a text which is based on measurable and controllable facts, as in annual reports or in technical documentation, an analysis of such a text would hardly create difficulties or distortions in the understanding of its purpose. Pathos, the appeal form which is directed towards the receiver's emotional side, is reflected in the choice of words, in the use of syntax and rhetorical figures. Senders, communicators or text authors should have to be very cautious in their choices, for an excessive use of pathos may result in 'pathetic' (p. 39). Ethos constructs the sender's credibility through its true virtues: phronesis (or competence), arete (or the ability to appear sympathetic) and eunoia (or the receiver's good will and benevolence).

Chapter 3 discusses the communicative purpose of a text which is achieved through speech acts, text functions and social motive. After Austin's and Searle's views on what have come to be known as the speech acts theory, the 'felicity conditions' together with Searle's classification of speech acts (pp. 49-51) are revisited and then the chapter continues with distinctions between direct and indirect speech acts. While the theory of speech acts typically suggests the communicative purpose of a minimal text with representation at sentence level, the concept of text functions introduced by Bühler (1934) accounts for the communicative purpose of a whole text. Again, an older model, Bühler's in this case, supplemented by Jakobson's more recent model (1990) are reminded and further completed with Helder's concept of social motive. The evolution of the syntagm social motive goes back to Burke's (1969) motive and situation as well as to Bitzer's (1968) exigence resumed into Miller's (1984: 57) exigence and which eventually becomes social motive in Lund's terminology (2004: 63), borrowed by Helder in this particular case. Social motive accounts for the impossibility of social needs, which are extremely diversified, to be classified the way text functions or speech acts are classified. Although this concept plays as an important role as the speech acts and text functions, at this point, the author restricts his presentation to a few chronological details and to a few case-relevant examples. I should say that bullet-pointed lists of all instances of social motives would have been more helpful to students and would have perfectly suited the book format since such lists do exist wherever necessary throughout the book (see, for example pp. $35,47,58,77,81$, etc.).

Chapter 4 explores the concept of move structure which refers to '(more or less) fixed structural patterns senders usually follow to express their purpose' (p. 69); it which distinguishes between general and specific move structures, and it finally exemplifies 'in more detail how the move structure works' (p. 80). In the case of general move structures, argumentative type, due to its persuasive purpose is more complex than the expository or the narrative types. In the case of specific move structures, the focus is on a couple of examples (the news report, pp. 75-76 and an advertisement, pp. 79-80). As a text genre, the press-release benefits from a more elaborate presentation in that two classifications are provided, the former considering the topic of the press release and the latter comprising the press release types. At this very point, with regard to the book structure, my view is different from the author's. The chapter develops two new infrastructures to analyze business letters and research article abstracts and introductions. I see these chapter sections as other illustrations of specific move structures actually supplementing the preceding examples of genre 
analysis. I consider business letters to be a text genre comparable with press-releases, for they may similarly be grouped in terms of their topic (into letters of invitation, offer, recommendation, endorsement, etc.) as well as in terms of addressee (letter to the editor - of a newspaper, review or journal, letters to institutions, such as parliament, congress, senate or government, to political personalities, etc.). In my opinion, the same holds true for the next couple of examples, referring to research article abstracts and introductions. In spite of this tiny observation, the high quality of the book is remarkable throughout the review. Given the particularities of academic subjects and their related fields, the author chooses to first present the move structure of medical research papers which is strictly domain-related and then to continue with a structural characterization of abstracts and introductions, which are more or less similar, no matter the specialist field.

Chapter 5 is designed to characterize the basic models of writing or text types, viz., exposition, narration, description, instruction and argumentation. Although narration is more frequent in fiction, it may be found in professional texts "where background information about a problem, condition, company" (p. 100), etc. is required. The argumentative text, typically intended "to conquer the receiver's doubt through reasoning" (p. 108) and based on Aristotle's syllogism and enthememe as well as the deductive and inductive directions of generalization have become technically more sophisticated, in recent years. To account for this progress, Helder again resorts to a well-known model, namely Toulmin's model of argumentation (1969), which he presents in detail and, which for practical purposes he summarizes in a tabular form (p. 114). With all these specifications, the predominantly theoretical strand of the book is closed.

Chapter 6 opens a new strand where the practical element is predominantly displayed a fourchapter presentation of rhetorical strategies. This chapter revisits Grice's text interpreting elements, namely the cooperative principle and its maxims, implicature and inference, to introduce topoi, a complex argumentation-related concept providing support from various mental 'places' or 'sites' (p. 123). In textual analyses, flawed arguments or fallacies may be related to the maxim of quality (pp. 129-133) as well as to the process of reasoning which is substantiated through deductive, inductive or some other miscellaneous types of reasoning (pp. 135-137). To perform a thorough analysis of a professional text, the text analyst is advised to question the sender's degree of certainty determinable with the help of hedging, a notion indicating that the sender "a) may not be totally accurate, b) may be superfluous, c) may not be relevant or d) may not make sense" (p. 139).

Chapter 7 insists on two outlooks, the attitude of the sender and the sender/receiver relationship. Within the attitude of the sender, style is seen as individual use of language/usage, as deviation from the norm and as choice, which is actually required by the situation of communication (p. 145). Then, the levels of formality are seen thorough two different perspectives, that of Joos (1967) and that of Quirk et al. (1985). Then, the syntagm text perspective is delimited as a concept which may be either sender-oriented or receiver-oriented, and wherein lexical choices may prove their analytical relevance. Within the sender/receiver relationship, the use of deictic elements, the possibility of determining the degree of politeness as well as the selection of lexical and syntactic elements which concur to the analysis of a text level of formality are discussed. In addition, the point of view which permeates a text or a perspective together with the use of voice will play a role in determining the central or the shifting perspective of the text in question.

The text-related notion of coherence and the sentence-related notion of cohesion as well as the means by which they are created represent the essence of Chapter 8 . Helder's model of textual interpretation suggests that an analysis of the information structure should take into consideration a wide range of syntactic devices, beginning with the structure of sentences and then inquiring the use of verb patterns, active and passive constructions and the roles of participants (actors and agents). A text analyst should also examine the sender's preference for the nominal vs the verbal style as well as the choices between left-branching and right-branching which are stylistic devices related to the sentence, clause or phrase word order. In the case of left-branching, the examples show (a) long subjects (expressed by complex noun phrases with both pre- and post-modification) 
which hold a front position, and (b) long adverbials are placed before the subject and the verb (p. 199). In the latter case, the right-branched constructions are 'the heavy constituents appearing at the end of a structure [...] after the verb' (p. 199).

The briefest chapter of the book, chapter 9, presents 'the most common rhetorical devices' (p. 203) or tropes and figures used in professional texts. Out of the rhetorical means which were minutely described in famous volumes (see, for example Fontanier 1968 or Genette 1966), this chapter presents but tropes as rhetorical questions, metaphors, similes, irony, hyperbole, litotes and personification and figures as climax, anaphora, epiphora, antithesis and evidence. Nevertheless, the only appendix of the book which is entitled Tropes and figures proceeds to completing the inventory of rhetorical strategies with a considerable number of other such stylistic resources. Furthermore, they are classified into various categories, which include, among others: tropes of degree, plays on sound and sense, plays on logic, figures of repetition, figures of omission, etc. (pp. 221-231).

The final chapter, with its equational title, summary - analysis sheet is so devised as to serve two purposes: to overview the main ideas in the book, which are formulated here as questions under each chapter title and (if the title chapter is omitted) to provide a questionnaire of great help for a beginner, who embarks upon the analysis of professional texts. A well sustained answer to each of these questions will eventually lead to an in-depth analysis of any professional text.

\section{Concluding remarks}

I consider this book to be a valuable addition to literature, both for its informative value and for its user-friendly and highly practical format. First, the book revises models applicable in analytical approaches to professional texts; while few of them are merged into new representations, most often they are so adapted or supplemented with new concepts as to make a textual analysis meet the present-day requirements of interpreting practices. Secondly, the book is user-friendly for it is economically tailored: it opens directly with chapter 1 which is both a book introduction, making some very sketchy references to the topic of each chapter, and a framework for much of what is presented herein will never be resumed anywhere else in the book. Thirdly, the book is practical for it usefully merges theoretical information with carefully selected self-speaking excerpts and with illustrative textual analyses which will certainly prove to be inspiring examples for its readers. The author deserves congratulations for his originally designed book thus created as to ensure the specific progression of textual analysis skills.

\section{References}

Austin, John Langshaw 1962: How to do things with words. Cambridge, MA: Harvard University Press.

Bitzer, F. Lloyd 1968: The Rhetorical Situation. In Philosophy and Rhetoric 1, 1-14.

Bühler, Karl 1934: Sprachtheorie. Die Darstellungsfunktion der Sprache. Jena: Gustav Fischer.

Burke, Kenneth 1969: A Rhetoric of Motives. California: University of California Press.

Fontanier, Pierre 1968: Les Figures du Discours. Paris: Flammarion.

Genette, Gerard 1966: Figures. Paris: Editions du Seuil.

Grice, Pierce 1975: Logic and Conversation. In Cole, P./Morgan, J.L. (eds.), Syntax and Semantics 3: Speech Acts. New York Academic Press, 41-58.

Jakobson, Roman 1990: Lectures on Sound \& Meaning. In On Language. Cambridge: MIT Press.

Jakobson, Roman 1960: Closing Statement: Linguistics and Poetics. In Sebeok, Thomas A. (ed.), Style In Language. Cambridge, Massachusetts: MIT Press, 350-77.

Joos, Martin 1967: The Five Clocks. A Linguistic excursion into the five styles of English Usage. New York: Harcourt.

Laswell, Harold Dwight 1948: The structure and function of communication in society. In Bryson, L. (ed.), The communication of ideas. New York: Harper.

Lund, Anne Katrine 2004: Den forsømte kommunikation - brevet i organisationskommunikationen. Frederiksberg: Samfundslitteratur.

Miller, Carolyne 1984: Genre as Social Action. In Quarterly Journal of Speech 70, 151-67. 
Quirk, Randolph et al. 1985: A Comprehensive Grammar of the English language. London/New York: Longman. Searle, John 1969: Speech Acts: An Essay in the Philosophy of Language, Cambridge: Cambridge University Press. Toulmin, Stephen 1969: The Uses of Argument. Cambridge: Cambridge University Press.

Floriana Popescu 
